\title{
Beyond COVID-19 deaths during the COVID-19 pandemic in the United States
}

\author{
Sheldon H. Jacobson ${ }^{1}$ (D) - Janet A. Jokela ${ }^{2}$ \\ Received: 21 April 2021 / Accepted: 10 June 2021 / Published online: 30 June 2021 \\ (C) The Author(s), under exclusive licence to Springer Science+Business Media, LLC, part of Springer Nature 2021
}

\begin{abstract}
COVID-19 has disrupted society and health care systems, creating a fertile environment for deaths beyond the virus. The year 2020 will prove to be the most deadly year on record in the United States. Direct deaths due to COVID-19 have been well documented and reported. Older people (those over 65) have been hardest hit, with over $80 \%$ of the COVID-19 deaths in this age group. What has been less clear is the impact on those under 65 years old, particularly those under 44 years old. This study considers both COVID-19 deaths and non-COVID-19 deaths during a 39 weeks period beginning 1 March in both 2020 and averaged over the five years from 2015 to 2019. Across 22 age and gender cohorts, death risks are compared using odds ratios. The results indicate that younger people (those under 15 years old) have experienced the same or a reduction in death risk between 2020 and the average from 2015 to 2019, suggesting that societal changes were protective for some of them. With all COVID-19 deaths removed from the 2020 death counts, 15-64 year olds experienced increased death risk between 2020 and the 2015 to 2019 average. For example, 15-44 year old males experienced a significant increase in their death risk, even though the absolute number of COVID-19 deaths for this cohort is small. The key take away from this study is that COVID-19 resulted in a large number of additional deaths in 2020 compared to the average from 2015 to 2019 , both directly from the virus and indirectly due to societal responses to the virus.
\end{abstract}

Keywords Covid-19 $\cdot$ Risk analysis $\cdot$ Odds ratios

\section{Background}

It probably will be confirmed that more people died in the United States in 2020 than in any previous year on record $[1,8,14]$, with COVID-19 the driving factor for many of these deaths $[5,13]$. However, COVID-19 also precipitated major societal changes, such as stay-at-home orders, school closings, and widespread reductions in business and leisure travel. With hospital systems consumed with caring for COVID-19 patients, challenges arose with treating other chronic and acute

Sheldon H. Jacobson

shj@illinois.edu

Janet A. Jokela

jokela@illinois.edu

1 Department of Computer Science, Carle Illinois School of Medicine, University of Illinois, Urbana, IL 61801, USA

2 University of Illinois College of Medicine at Urbana, Urbana, IL 61801, USA conditions, and providing preventive screening [4]. Although it is still too early to measure the full impact of such disruptions, it is hypothesized that such issues have contributed to more deaths which under prior circumstances would have been avoided $[7,9,10]$.

The objective of this analysis is to measure such impacts. This is done by estimating death risks (defined as the odds of dying) both including and excluding COVID-19 deaths in the US by age and gender from 1 March 2020 through 28 November 2020, a period of 39 weeks (labelled as the designated time period). This is compared to death risks during the same time period, with deaths and population averaged from 2015 to 2019 (for brevity, this will be referred to as 20152019 death risks).

\section{Methods}

The US Centers for Disease Control and Prevention (CDC) reports the total number of US provisional deaths from all causes including those directly attributed to COVID-19 [2]. 
The difference between deaths from all causes and those due to COVID-19 provides the number of non-COVID-19 deaths in 2020 .

This paper compares death risks both including and excluding COVID-19 deaths across 22 age and gender cohorts in the US during the designated time period to the 2015-2019 death risks during the designated time period [1]. By subtracting COVID-19 deaths from the total death counts in 2020, the resulting analysis provides one approach to capture the potential societal mortality impact of COVID-19 not directly due to COVID-19. It also accounts for deaths in 2020 that would have occurred independent of COVID-19 even though they may have been attributed to COVID-19, providing a means to determine if other causes of deaths changed from the previous five years to 2020. Odds ratios [12] are used to quantify the relative death risks between 2020 and 2015 to 2019 during the designated time period for the 22 age and gender cohorts.

\section{Results}

Table 1 (columns 2-5) reports 99\% confidence intervals for the odds ratios between the death risks during the designated time period in 2020 and the 2015 to 2019 death risks during the same 39 -week time period for 22 age and gender cohorts. Columns 6-9 of the table reports the same estimators with COVID-19 deaths excluded.

For a given age and gender cohort, a $2 \times 2$ contingency table is constructed with the number of deaths and number not dying for 2020 and the same data type averaged from 2015 to 2019 [12]. To illustrate, consider the 25-34 year old female cohort. Then for 2020 , let $\beta 1=$ number of deaths in this cohort during the designated time period, and $\beta 2=$ number of people in this cohort that did not die in the designated time period. Using data from 2015 to 2019 , let $\delta 1=$ average number of deaths (per year) in this cohort during the designated time period, and $\delta 2=$ average number of people in this cohort that did not die (per year) in the designated time period. Then the odds ratio point estimator is given by

$\mathrm{OR}=(\beta 1 / \beta 2) /(\delta 1 / \delta 2)$,

with $99 \%$ confidence interval for the odds ratio given by

$\exp \left[\ln (\mathrm{OR}) \pm Z_{0.005}((1 / \beta 1)+(1 / \beta 2)+(1 / \delta 1)+(1 / \delta 2))^{1 / 2}\right]$

where $\exp$ denotes the exponential function, In the natural logarithm function, and $\mathrm{Z}_{0.005}$ the 0.005 tail probability for the standard normal distribution.

We report $99 \%$ confidence intervals, as opposed to $95 \%$ confidence intervals, to mitigate the Bonferroni effect when interpreting coverage across multiple confidence intervals simultaneously [6]. In addition, $p$ values for the odd ratios are given, based on two-sided hypothesis tests with the alternative hypothesis given as the odds ratio not equal to one.

Tables 2 provides the male deaths for the designated time period across the 11 age groups in 2020 and deaths averaged between 2015 and 2019. Table 3 contains the same data for females. For 2020, both deaths from all causes and nonCOVID-19 deaths (deaths from all causes minus deaths directly attributed to COVID-19) are given.

\section{Discussion}

We first assess whether there is a statistically significant difference in the odds ratios between the two genders. The log of the odds ratios are asymptotically normal, which is the case given the large values for the death counts and populations in each age and gender cohort in the $2 \times 2$ contingency tables

Table 1 99\% Odds Ratio Confidence Intervals Comparing Death Risks in 2020 and 2015-2019

\begin{tabular}{|c|c|c|c|c|c|c|c|c|}
\hline $\begin{array}{l}\text { Age } \\
\text { Cohort }\end{array}$ & $\begin{array}{l}\text { Odds Ratio (All } \\
\text { Cause Males } \\
\text { Deaths) }\end{array}$ & $\mathrm{p}$ value & $\begin{array}{l}\text { Odds Ratio (All } \\
\text { Cause Female } \\
\text { Deaths) }\end{array}$ & $\mathrm{p}$ value & $\begin{array}{l}\text { Odds Ratio (Males } \\
\text { Deaths Excluding } \\
\text { COVID-19) }\end{array}$ & $\mathrm{p}$ value & $\begin{array}{l}\text { Odds Ratio (Female } \\
\text { Deaths Excluding } \\
\text { COVID-19) }\end{array}$ & $\mathrm{p}$ value \\
\hline$<1$ & $(0.822,0.889)$ & $<0.001$ & $(0.817,0.892)$ & $<0.001$ & $(0.819,0.886)$ & $<0.001$ & $(0.815,0.890)$ & $<0.001$ \\
\hline $1-4$ & $(0.819,0.982)$ & 0.002 & $(0.767,0.950)$ & $<0.001$ & $(0.814,0.977)$ & $<0.001$ & $(0.760,0.942)$ & $<0.001$ \\
\hline $5-14$ & $(1.004,1.163)$ & 0.006 & $(0.900,1.075)$ & 0.63 & $(0.989,1.147)$ & 0.027 & $(0.889,1.062)$ & 0.40 \\
\hline $15-24$ & $(1.170,1.234)$ & $<0.001$ & $(1.113,1.217)$ & $<0.001$ & $(1.153,1.216)$ & $<0.001$ & $(1.082,1.184)$ & $<0.001$ \\
\hline $25-34$ & $(1.251,1.301)$ & $<0.001$ & $(1.204,1.279)$ & $<0.001$ & $(1.209,1.258)$ & $<0.001$ & $(1.148,1.221)$ & $<0.001$ \\
\hline $35-44$ & $(1.309,1.355)$ & $<0.001$ & $(1.208,1.267)$ & $<0.001$ & $(1.220,1.264)$ & $<0.001$ & $(1.130,1.185)$ & $<0.001$ \\
\hline $45-54$ & $(1.219,1.250)$ & $<0.001$ & $(1.121,1.158)$ & $<0.001$ & $(1.090,1.119)$ & $<0.001$ & $(1.024,1.058)$ & $<0.001$ \\
\hline $55-64$ & $(1.188,1.209)$ & $<0.001$ & $(1.144,1.169)$ & $<0.001$ & $(1.057,1.075)$ & $<0.001$ & $(1.034,1.057)$ & $<0.001$ \\
\hline $65-74$ & $(1.171,1.188)$ & $<0.001$ & $(1.126,1.146)$ & $<0.001$ & $(1.018,1.033)$ & $<0.001$ & $(0.997,1.015)$ & 0.073 \\
\hline $75-84$ & $(1.133,1.149)$ & $<0.001$ & $(1.110,1.126)$ & $<0.001$ & $(0.973,0.987)$ & $<0.001$ & $(0.975,0.990)$ & $<0.001$ \\
\hline $85+$ & $(1.136,1.153)$ & $<0.001$ & $(1.149,1.162)$ & $<0.001$ & $(0.975,0.991)$ & $<0.001$ & $(1.003,1.015)$ & $<0.001$ \\
\hline
\end{tabular}


[12]. Then we apply paired difference Student-t tests for both all causes of deaths and non-COVID-19 deaths over the 11 age groups. For both the all causes of deaths and non-COVID19 deaths, the two-sided $p$ values are both less than 0.005 , which suggests that the odds ratios for males and females can be analyzed separately.

In Table 1 (columns 2-5), for 16 of the 22 age and gender cohorts (15-85+ years old), the odds ratio confidence intervals indicate a statistically significant increase in death risks in 2020 compared to 2015-2019 death risks. For females, the 25-34 years old cohort has the highest observed odds ratio (1.124), while for males, the 35-44 years old cohort has the highest observed odds ratio (1.332). For five age cohorts (covering those 35-84 years old), the odds ratios for the two genders did not overlap, indicating males in these age cohorts experienced a higher death risk increase than females. In addition, the $p$ values for these odds ratios are all less than 0.001 .

Males and females under 4 years for age showed a statistically significant decrease in death risk. These findings do not suggest that COVID-19 is beneficial for these children, but that other factors, such as societal changes brought about by COVID-19, shielded them from events such as unintentional injuries and accidents [3], which represent the leading cause of death amongst these groups. For example, stay-at-home orders resulted in fewer automobile accidents since fewer people drove their vehicles and fewer miles were driven [11]. Such insights can be useful to identify ways to keep young children safe as society transitions to more interactive interpersonal engagement and movement.

Given that the CDC reports COVID-19 deaths daily [8], the question arises whether these deaths represent additive deaths, or substitute deaths. To help answer this question, the COVID19 deaths are subtracted from the 2020 death totals, with the resulting death risks compared to the 2015-2019 death risks.
In Columns 6-9 of Table 1, for 11 of the 22 age and gender cohorts (females 15-64 years old, males 15-74 years old), the odds ratio confidence intervals indicate a statistically significant increase in non-COVID-19 death risk in 2020 compared to 2015-2019 death risks. The 25-34 years old female and the 35-44 years old male cohorts show the highest observed odds ratios. For those 35-64 years old, the odds ratios for the two genders did not overlap, indicating males in these age cohorts experienced a higher non-COVID-19 death risk increase than females. In addition, $p$ values less than 0.001 provide statistical support that non-COVID-19 death risks as measured by the odds ratio changed in 2020 compared to the 2015-2019 death risks.

Tables 2 and 3 provide the actual average death counts from 2015 to 2019 and both the all cause and non-COVID19 death counts for 2020 . These numbers corroborate the increase in death risk in 2020 versus the average from 2015 to 2019, even removing direct COVID-19 deaths [13]. Excluding COVID-19 deaths, for example, 1224 fewer male infants $(<1$ years old) and 983 fewer female infants died in 2020 compared to the average number of deaths from 2015 to 2019. In addition, 2992 additional non-COVID-19 deaths occurred amongst 15-24 year old males in 2020 compared to the average number of deaths from 2015 to 2019, an increase of $17 \%$, and 8438 additional non-COVID-19 deaths occurred amongst 25-34 year old males in 2020 compared to the average number of deaths from 2015 to 2019, an increase of $28 \%$. Similar decreases and increases are reported for females in these age groups. Though the absolute number of COVID19 deaths in these cohorts was small (see column 4 in Tables 2 and 3), the impact of COVID-19 on society had a deleterious impact on them. The cause of such additional nonCOVID-19 deaths is unclear at this time. Possibilities include opioid overdoses, domestic violence, or suicide. Another possibility is that COVID-19 deaths were simply undetected,

Table 2 COVID-19 and Non-COVD-19 Deaths in 2020 and 2015-2019 (Males), Designated Time Period

\begin{tabular}{lllllll}
\hline $\begin{array}{l}\text { Age } \\
\text { Cohort }\end{array}$ & $\begin{array}{l}\text { All Cause Male } \\
\text { Deaths (2020) }\end{array}$ & $\begin{array}{l}\text { Non-COVID-19 } \\
\text { Male Deaths (2020) }\end{array}$ & $\begin{array}{l}\text { Percentage of Deaths Attributed } \\
\text { to COVID-19 (2020) }\end{array}$ & $\begin{array}{l}\text { Male } \\
\text { Population } \\
(2020)\end{array}$ & $\begin{array}{l}\text { All Cause Male Deaths } \\
\text { Average (2015-19) }\end{array}$ & $\begin{array}{l}\text { Average Male } \\
\text { Population (2015- } \\
19)\end{array}$ \\
\hline$<1$ & 8070 & 8043 & $.33 \%$ & $2,112,227$ & 9267 & $2,074,811$ \\
$1-4$ & 1532 & 1523 & $.59 \%$ & $8,407,948$ & 1675 & $8,246,467$ \\
$5-14$ & 2560 & 2523 & $1.45 \%$ & $20,944,619$ & 2369 & $20,945,141$ \\
$15-24$ & 20,556 & 20,261 & $1.44 \%$ & $22,048,975$ & 17,269 & $22,246,948$ \\
$25-34$ & 40,104 & 38,762 & $3.35 \%$ & $23,942,277$ & 30,324 & $23,085,425$ \\
$35-44$ & 51,882 & 48,368 & $6.77 \%$ & $21,370,925$ & 37,464 & $20,538,688$ \\
$45-54$ & 90,519 & 81,031 & $10.48 \%$ & $20,191,496$ & 75,952 & $20,890,268$ \\
$55-64$ & 201,923 & 179,741 & $10.99 \%$ & $20,798,044$ & 164,672 & $20,298,286$ \\
$65-74$ & 289,089 & 251,955 & $12.83 \%$ & $15,467,151$ & 221,253 & $13,924,304$ \\
$75-84$ & 313,347 & 270,795 & $13.58 \%$ & $7,320,885$ & 245,104 & $6,497,419$ \\
$85+$ & 286,109 & 249,857 & $12.67 \%$ & $2,431,872$ & 238,236 & $2,283,305$ \\
Total & $1,305,641$ & $1,152,859$ & $11.70 \%$ & $165,036,419$ & $1,043,584$ & $161,031,064$ \\
\hline
\end{tabular}


Table 3 COVID-19 and Non-COVD-19 Deaths in 2020 and 2015-2019 (Females) Designated Time Period

\begin{tabular}{lllllll}
\hline $\begin{array}{l}\text { Age } \\
\text { Cohort }\end{array}$ & $\begin{array}{l}\text { All Cause Female } \\
\text { Deaths (2020) }\end{array}$ & $\begin{array}{l}\text { Non-COVID-19 } \\
\text { Female Deaths (2020) }\end{array}$ & $\begin{array}{l}\text { Percentage of Deaths } \\
\text { Attributed to COVID-19 } \\
(2020)\end{array}$ & $\begin{array}{l}\text { Female } \\
\text { Population } \\
(2020)\end{array}$ & $\begin{array}{l}\text { All Cause Female Deaths } \\
\text { Average (2015-19) }\end{array}$ & $\begin{array}{l}\text { Average Female } \\
\text { Population (2015- } \\
19)\end{array}$ \\
\hline$<1$ & 6434 & 6420 & $.22 \%$ & $2,016,583$ & 7403 & $1,980,868$ \\
$1-4$ & 1082 & 1073 & $.83 \%$ & $8,030,910$ & 1244 & $7,877,762$ \\
$5-14$ & 1676 & 1655 & $1.25 \%$ & $20,064,260$ & 1704 & $20,070,928$ \\
$15-24$ & 7173 & 6977 & $2.73 \%$ & $21,057,902$ & 6198 & $21,177,766$ \\
$25-34$ & 16,532 & 15,777 & $4.57 \%$ & $22,947,659$ & 12,966 & $22,327,934$ \\
$35-44$ & 27,228 & 25,474 & $6.44 \%$ & $21,256,845$ & 21,305 & $20,570,072$ \\
$45-54$ & 53,144 & 48,565 & $8.62 \%$ & $20,650,440$ & 48,390 & $21,416,787$ \\
$55-64$ & 125,269 & 113,250 & $9.59 \%$ & $22,221,321$ & 106,091 & $21,752,162$ \\
$65-74$ & 207,333 & 183,905 & $11.30 \%$ & $17,608,023$ & 164,330 & $15,829,518$ \\
$75-84$ & 287,723 & 253,805 & $11.79 \%$ & $9,318,438$ & 232,697 & $8,398,757$ \\
$85+$ & 450,825 & 398,990 & $11.50 \%$ & $4,294,658$ & 386,346 & $4,192,508$ \\
Total & $1,184,419$ & $1,055,891$ & $10.85 \%$ & $169,467,039$ & 988,675 & $165,595,063$
\end{tabular}

hence not reported or not attributed to the virus. Further research is needed to better assess the causes of such deaths, so appropriate preventive steps can be taken to protect such individuals in the future.

\section{Conclusions}

This analysis reports that a large segment of the population experienced a statistically significant increase in death risk in 2020 compared to 2015 to 2019, even with direct COVID-19 deaths subtracted from the death counts. Moreover, the youngest age cohorts experienced a statistically significant decrease in non-COVID-19 death risk. Although the number of COVID-19 deaths in some age cohorts is small, the death risk changes are statistically significant, both including and excluding COVID-19 deaths. These findings illustrate the widespread impact of COVID-19 across the entire US population, with the resulting changes in death risks touching every age and gender cohort.

Availability of data and material All data used is publicly available with citation to data repositories.

Authors' information SHJ is a data scientist with research expertise applied to public health and public policy problems. JAJ is an infectious disease physician with interests in public health.

Code availability Not Applicable.

Authors' contributions Both authors contributed to the ideas that led to the paper. SHJ contributed to the statistical analysis, the literature review, and the manuscript preparation. JAJ contributed to the concept and provided background on infectious diseases and public health. SHJ wrote the first draft of the paper. JAJ provided extensive feedback and comments. Both authors read and approved the final version of the manuscript.

\section{Declarations}

Conflicts of interest/competing interests Authors declare no conflicts of interest.

Ethics approval and consent to participate No ethical approval was required for this study. The analysis uses only publicly available data reported in the literature.

Consent for publication Not Applicable.

\section{References}

1. CDC (2020) “CDC Wonder” Accessed May 29, 2021, Available at https://wonder.cdc.gov/

2. CDC (2020) "Provisional COVID-19 deaths counts by sex, age, and week" Accessed May 29, 2021, Available at https://data.cdc. gov/NCHS/Provisional-COVID-19-Death-Counts-by-Sex-Ageand-W/vsak-wrfu

3. Cunningham RM, Walton MA, Carter PM (2018) The major causes of death in children and adolescents in the United States. N Engl $\mathrm{J}$ Med 379:2468-2475. https://doi.org/10.1056/NEJMsr1804754

4. Czeisler ME, Marynak K, Clarke KE et al (2020) Delay or Avoidance of Medical Care Because of COVID-19 - Related Concerns - United States. June 2020. MMWR Morb Mortal Wkly Rep 69:1250-1257

5. Faust JS, Krumholz HM, Du C, et al. (2020) "All-Cause Excess Mortality and COVID-19-Related Mortality Among US Adults Aged 25-44 Years, March-July 2020." JAMA. Published online December 16, 2020. https://doi.org/10.1001/jama.2020.24243

6. Haynes W (2013) Bonferroni correction. In: Dubitzky W, Wolkenhauer O, Cho KH, Yokota H (eds) Encyclopedia of systems biology. Springer. https://doi.org/10.1007/978-1-4419-9863-7 1213

7. Jacobson SH, Jokela JA (2021) Non-Covid-19 excess deaths by age and gender in the United States during the first three months of the Covid-19 pandemic. Public Health 189:101-103

8. Hopkins J (2020) "Johns Hopkins Resource Center," Accessed May 29, 2021, Available at https://coronavirus.jhu.edu/ 
9. Kontis V, Bennett JE, Rashid T, Parks RM, Pearson-Stuttard J, Guillot M, Asaria P, Zhou B, Battaglini M, Corsetti G, McKee M, di Cesare M, Mathers CD, Ezzati M (2020) Magnitude, demographics and dynamics of the effect of the first wave of the COVID19 pandemic on all-cause mortality in 21 industrialized countries. Nat Med 26:1919-1928. https://doi.org/10.1038/s41591-020$1112-0$

10. Lu D (2020) "2020 Was Especially Deadly. Covid Wasn't the Only Culprit." New York Times, Published 13 December 2020. Accssed 22 May 2021 at https://www.nytimes.com/interactive/2020/12/13/ us/deaths-covid-other-causes.html

11. Meyer MW (2020) "COVID lockdowns, social distancing, and fatal Car crashes: more deaths on Hobbesian highways?" Camb J Evid Based Polic. 4. 238-259. https://doi.org/10.1007/s41887-02000059-8, 4, 238, 259
12. Tenny S, Hoffman MR (2021) Odds ratio, [updated 2020 Jul 10]. In: StatPearls [internet]. Treasure Island (FL): StatPearls publishing; 2021 Jan-. Available from: https://www.ncbi.nlm.nih.gov/books/ NBK431098/

13. Woolf SH, Chapman DA, Lee JH (2020) "COVID-19 as the Leading Cause of Death in the United States." JAMA. Published online December 17, 2020. https://doi.org/10.1001/jama.2020. 24865

14. Woolf SH, Chapman DA, Sabo, RT (2021) "Excess deaths from COVID-19 and other causes in the US, march 1, 2020, to January 2, 2021" JAMA. Published online April 2, 2021. https://doi.org/10. 1001/jama.2021.5199

Publisher's note Springer Nature remains neutral with regard to jurisdictional claims in published maps and institutional affiliations. 